\title{
Rocket Combustion Properties for Coaxial Injectors Operated at Elevated Pressures
}

\author{
S. Alexander Schumaker ${ }^{*}$ and James F. Driscoll ${ }^{\dagger}$ \\ The University of Michigan, Department of Aerospace Engineering, 1320 Beal Avenue, Ann Arbor, MI 48109
}

\begin{abstract}
A new facility has been built at the University of Michigan to study shear coaxial combusting gas-gas injection in a rocket combustion chamber. This facility, capable of chamber pressures of 10 atmospheres, is used to obtain a better understanding of the complex fluid dynamics and combustion processes found in rocket combustion chambers and to provide data to assess NASA's computational fluid dynamics codes. Visual flame images obtained at chamber pressures of 1 and 7.5 atmospheres are presented here. From these images visual flame lengths are calculated. The observed trends are consistent with pervious work in turbulent variable density shear layers.
\end{abstract}

\section{Nomenclature}

$\begin{array}{ll}d_{x} & =\text { Injector diameter associated with species } \mathrm{x} \\ f_{s} & =\text { Stoichiometric mixture fraction based on inner jet fluid } \\ L & =\text { Distance downstream from injector face } \\ L_{f} & =\text { Visual flame length } \\ \dot{m}_{x} & =\text { Mass flow rate of species } \mathrm{x} \\ O / F & =\text { Oxidizer to fuel mass ratio } \\ \rho_{x} & =\text { Density of species } \mathrm{x} \text { at the chamber pressure } \\ T_{\text {inlet }} & =\text { Temperature of propellants at injection } \\ V_{x} & =\text { Injection velocity of species } \mathrm{x}\end{array}$

\section{Introduction}

One of the goals of the NASA Constellation program is to design the next generation rocket engines to be used for the return-to-moon and mars missions. Empirically based design tools used in the past to design injectors and combustion chambers are being replaced by computational fluid dynamics (CFD) ${ }^{1}$. Due to the highly turbulent chemically reacting flows found in such systems, an improved understanding of the complex fluid dynamics and combustion processes are needed for model development along with benchmark data sets for code validation.

While current engine designs call for the use of LOX, gas-gas rocket combustion is an important part of model design and validation. Boundary conditions are known and it avoids the problem of assuming a spray distribution to assess the combustion and mixing models. Use of gas-gas also makes possible the use of Planar Laser Induced Florescence (PLIF) techniques to measure local O/F ratios, mixing patterns, mixing distances, and reaction zone locations and thicknesses that are required for code validation.

Research efforts addressing gas-gas shear coaxial rocket injectors to date, have focused on obtaining flow field data such as velocity field and species measurements using laser velocimetry, Raman spectroscopy, and OH LIF techniques $^{2-8}$. Additional gas-gas injector work has focused primary on the measurement of overall performance and not the flow field ${ }^{9}$. While these studies have addressed mixing at discrete points, the current data set is insufficient to address the variation in injection parameters needed for an in-depth mixing study of a shear coaxial rocket injector. Experimental and analytical work on near and far field mixing in cold flow coaxial jets and shear layers outline the dominate parameters and physics that affect the flow field in such configurations ${ }^{10-13}$. These indicate the velocity ratio, density ratio, inner jet diameter, stoichiometric mixture fraction, and jet momentum play important roles. Work by Dahm, Dimotakis, and others provide theory for the evolution of the flow field and relations for

\footnotetext{
* Graduate Student, Aerospace Engineering Department, The University of Michigan, Ann Arbor, MI, Member

${ }^{\dagger}$ Professor, Aerospace Engineering Department, The University of Michigan, Ann Arbor, MI, Fellow
} 
stoichiometric mixing lengths for such cases ${ }^{14-16}$. Issues that need to be addressed to apply these theories to an inverse jet flame in a rocket combustion environment include: modification of relations for the inverse jet flame case, the expansion of the theory to include affects of high pressure chemistry, and extending the density ratio range to include those for hydrogen and oxygen.

The current research effort focuses on applying mixing theories obtained for turbulent shear layers and coaxial jets to the case of an inverse gas-gas jet flame in a rocket combustion environment and providing a fundamental mixing gas-gas rocket combustion database for code validation. In this paper, the new facility designed and built to obtain this database is described. Visual flame images and calculated visual flame lengths are presented and discussed for a number of cases at chamber pressures of 1 and 7.5 atmospheres. Plans for future work also are presented.

\section{Experimental Setup}

To obtain flow field data for coaxial shear gas-gas rocket injectors, the Michigan Single Element Injector Experiment was designed and built. This facility is capable of combustion chamber pressures up to 10 atmospheres along with gaseous oxygen flow rates up to $5 \mathrm{~g} / \mathrm{s}$ and hydrogen flow rates up to $2 \mathrm{~g} / \mathrm{s}$. In addition to hydrogen, methane can also be used. This facility is described below.

\section{A. Test Apparatus}

The Michigan Single Element Injector Experiment is a laboratory scale rocket engine with optical access so laser based and visual diagnostic techniques can be utilized. The design and sizing of the rocket is based on work done at Penn State and NASA Marshall ${ }^{2,8,17}$. The rocket is of a modular design which allows a window section to be moved to any location in the combustion chamber and for the combustion chamber length to be varied by the addition or removal of spacer sections. A schematic of the rocket is shown in Fig. 1 and a photo is shown in Fig. 2. The rocket is comprised of sections including the nozzle assembly, injector assembly, window section, ignition block, and a number of spacer sections.

Every section of the rocket is machined from C145 tellurium copper. The rocket is held together using 4 threaded brass rods that run the length of the assembly. Between each section, a $0.79 \mathrm{~mm}$ thick high-temperature silicone gasket is used to seal the combustion chamber. The rocket is mounted in a vertical position on a Unistrut test stand, so the exhaust plume can directly enter the laboratory venting system.

The combustion chamber is $50.8 \mathrm{~mm} \times 50.8 \mathrm{~mm}$ square with $6.35 \mathrm{~mm}$ radius on the corners. For the present study, a configuration with a combustion chamber length of $266.70 \mathrm{~mm}$ was utilized for all tests. The nozzle assembly consists of an outer sleeve and an inner nozzle. This allows for a water cooling channel between the two pieces and for the inner nozzle diameter to be changed without the machining of a new outer sleeve. Different nozzle sizes allow for the chamber pressure to be varied for the same mass flow rate of propellants. A nozzle diameter of $3.56 \mathrm{~mm}$ was used for the 7.5 atmosphere cases. Ignition of the rocket is achieved using two opposed spark plugs located in the ignition block. The ignition block also contains a rupture disk that is designed to prevent window blowout in case of chamber over pressurization or detonation.

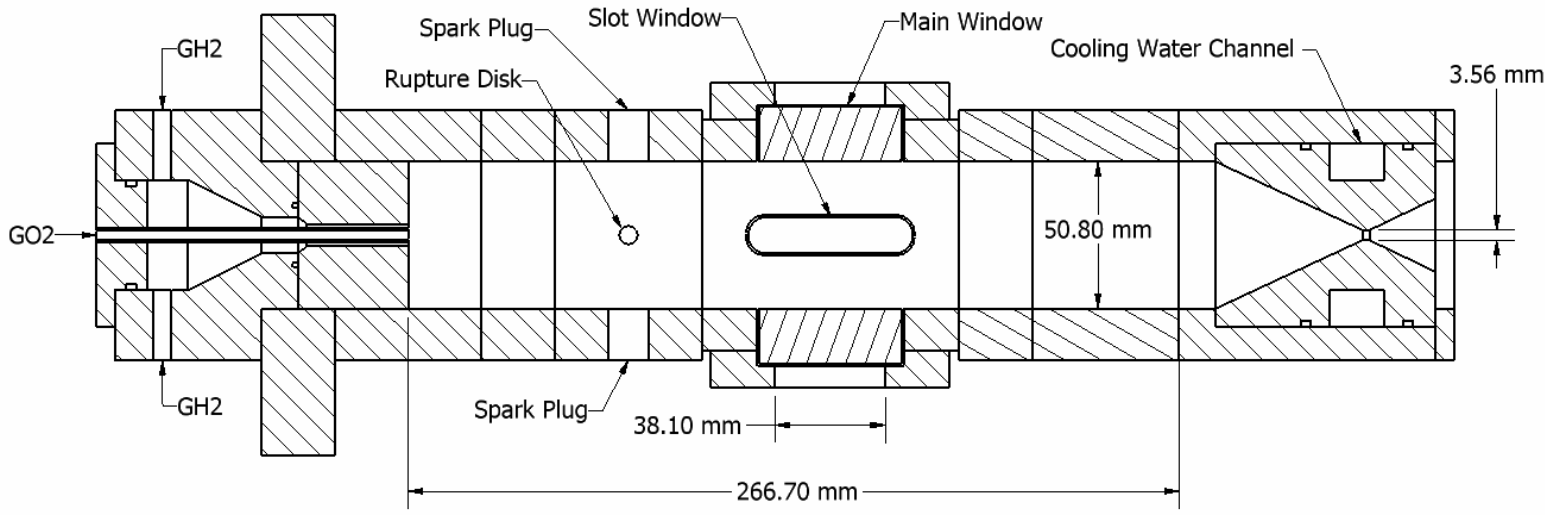

Figure 1. Schematic of the Michigan Single Element Injector Experiment

Optical access to the combustion chamber is provided by the $88.9 \mathrm{~mm}$ long window section. This section can be moved to any location in the combustion chamber, including the injector face. Two opposed $50.8 \mathrm{~mm} \times 50.8 \mathrm{~mm}$ windows with a $38.1 \mathrm{~mm} \times 38.1 \mathrm{~mm}$ viewable region, provide optical access to the combustion chamber, while two 
opposed $12.7 \mathrm{~mm} \times 57.15 \mathrm{~mm}$, $6.35 \mathrm{~mm}$ x $50.8 \mathrm{~mm}$ viewable, slot windows provide combustion chamber access for laser sheets. All windows are $19.05 \mathrm{~mm}$ thick fused quartz.

The injector assembly contains a single gas-gas shear coaxial injector and is shown in Fig. 3. Oxygen flows through the center tube surrounded by an annulus of hydrogen. The injector is of a modular design that allows the inner tube and the injector face plate to be modified, which allows the propellant injection velocities to be varied for a fixed mass flow rate. For the present study, a configuration with an oxygen tube inner diameter of $3.0 \mathrm{~mm}$, an oxygen tube outer diameter of $4.78 \mathrm{~mm}$ and a hydrogen annulus outer diameter of $7.52 \mathrm{~mm}$ is used in all cases. The oxygen tube is set to be flush with the injector face plate.

Data obtained at 1 atmosphere utilized a modified configuration of the rocket, where the nozzle and blank sections are removed and replaced by a quartz tube. The quartz tube is used so the whole flame, minus the base of the flame where the injector block was located, can be characterized without moving the window section and so ambient air cannot be entrained into the flame. The quartz tube is $279.4 \mathrm{~mm}$ long with an internal diameter of $53.98 \mathrm{~mm}$.

\section{B. Propellant Delivery System}

The propellant delivery system delivers gaseous fuel and oxidizer to the rocket experiment using remotely operated solenoid valves, which allows the experiment to be controlled from a control room located next to the laboratory. The fuel and oxidizer lines each have three solenoid valves. The first acts as a cut off to isolate the propellant supply from the rest of the system, allowing a second valve to open to purge the system remotely. The third solenoid valve is the fire valve which opens to start the delivery of propellants into the rocket. In addition to the solenoid valves, a

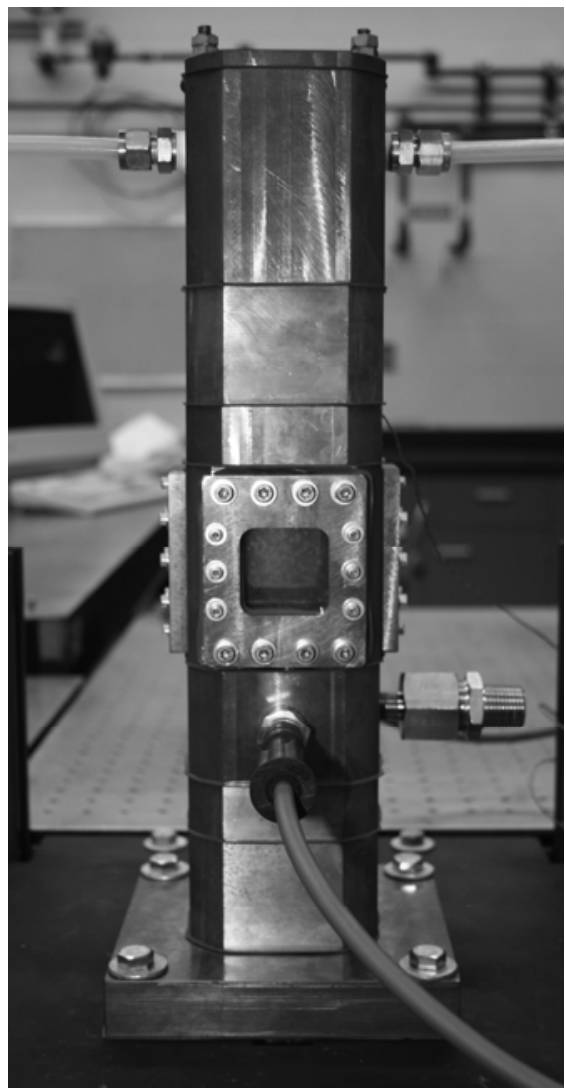

Figure 2. Photograph of the Michigan Single Element Injector Experiment number of relief and check valves are in place in case of regulator failure or rocket over pressurization and to prevent any premixing of the propellants in the delivery system. Mass flow is measured using choked orifices with pressure transducers and is controlled using a combination of regulators and needle valves. Due to a difficulty in setting the mass flow rates of the propellants when there is no flow through the system, an oxidizer vent valve and a fuel burner are integrated into the system that allow propellant to flow through the delivery system and bypass the combustion chamber. The utilization of this bypass allows the setting of a more accurate mass flow without forming a potentially dangerous combustible mixture in the rocket.

The test apparatus is controlled by LabVIEW software, utilizing two LabJack U12 data acquisition and control devices. The first uses differential analog inputs to monitor and record pressure in the combustion chamber, oxidizer line, and fuel line. The second uses digital I/Os to control the solenoid valves, ignition system and trigger any other data acquisition systems.

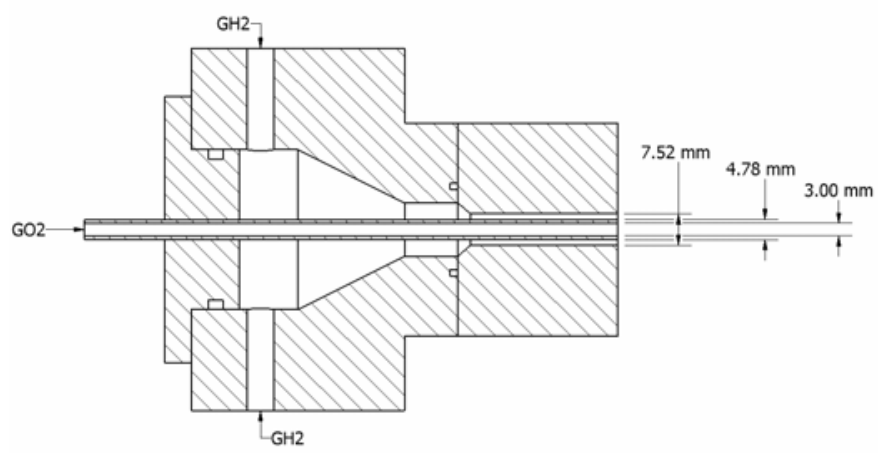

Figure 3. Schematic of shear coaxial injector used for all cases 


\section{Test Conditions}

Tests were conducted with chamber pressures of 1 and 7.5 atmospheres. Numerous cases were run at 1 atmosphere. Since no nozzle is used in these cases the pressure is not tied to the mass flow rates. However, since the same injector is used for all cases, the $\mathrm{O} / \mathrm{F}$ ratio prescribes a velocity ratio. Three $\mathrm{O} / \mathrm{F}$ ratios were studied: 2.67, 4, and 5.33. These $\mathrm{O} / \mathrm{F}$ ratios correspond to velocity ratios of $0.63,0.95$, and 1.27 respectively. Oxygen injection velocity was varied from $8.8 \mathrm{~m} / \mathrm{s}$ to $87.9 \mathrm{~m} / \mathrm{s}$, while hydrogen injection velocity was varied from $13.9 \mathrm{~m} / \mathrm{s}$ to 111.1 $\mathrm{m} / \mathrm{s}$. Using the described injector, the velocity values correspond to mass flow ranges of $0.03 \mathrm{~g} / \mathrm{s}$ to $0.25 \mathrm{~g} / \mathrm{s}$ and 0.16 $\mathrm{g} / \mathrm{s}$ to $0.82 \mathrm{~g} / \mathrm{s}$ for hydrogen and oxygen respectively. Parameters for a subset of these cases, which have visible flame images presented, are provided in Table 1.

Table 1. Subset of 1 atmosphere test cases

\begin{tabular}{|c|c|c|c|}
\hline & Case 1 & Case 2 & Case 3 \\
\hline \hline$\dot{m}_{H 2}$ & $0.19 \mathrm{~g} / \mathrm{s}$ & $0.12 \mathrm{~g} / \mathrm{s}$ & $0.09 \mathrm{~g} / \mathrm{s}$ \\
\hline$\dot{m}_{O 2}$ & $0.49 \mathrm{~g} / \mathrm{s}$ & $0.49 \mathrm{~g} / \mathrm{s}$ & $0.49 \mathrm{~g} / \mathrm{s}$ \\
\hline$O / F$ & 2.67 & 4.01 & 5.33 \\
\hline$V_{H 2}$ & $83.3 \mathrm{~m} / \mathrm{s}$ & $55.6 \mathrm{~m} / \mathrm{s}$ & $41.7 \mathrm{~m} / \mathrm{s}$ \\
\hline$V_{O 2}$ & $52.8 \mathrm{~m} / \mathrm{s}$ & $52.8 \mathrm{~m} / \mathrm{s}$ & $52.8 \mathrm{~m} / \mathrm{s}$ \\
\hline$V_{O 2} / V_{H 2}$ & 0.63 & 0.95 & 1.27 \\
\hline$T_{\text {Inlet }}$ & $294 \mathrm{~K}$ & $294 \mathrm{~K}$ & $294 \mathrm{~K}$ \\
\hline
\end{tabular}

For the 7.5 atmosphere tests, three cases were considered. A summery of the conditions for these cases is provided in Table 2. Since the same nozzle and injector were used for all cases, for a given O/F ratio and chamber pressure, only a single combination of mass flow rates was possible. Also note that for a given injector configuration, O/F ratio, and chamber pressure, the velocity ratio is prescribed. Velocity ratio is defined as oxygen velocity to hydrogen velocity.

Table 2. 7.5 atmosphere test cases

\begin{tabular}{|c|c|c|c|}
\hline & Case 4 & Case 5 & Case 6 \\
\hline \hline$\dot{m}_{H 2}$ & $1.49 \mathrm{~g} / \mathrm{s}$ & $1.28 \mathrm{~g} / \mathrm{s}$ & $1.12 \mathrm{~g} / \mathrm{s}$ \\
\hline$\dot{m}_{O 2}$ & $2.51 \mathrm{~g} / \mathrm{s}$ & $2.68 \mathrm{~g} / \mathrm{s}$ & $2.82 \mathrm{~g} / \mathrm{s}$ \\
\hline$O / F$ & 1.68 & 2.10 & 2.52 \\
\hline$V_{H 2}$ & $89.7 \mathrm{~m} / \mathrm{s}$ & $76.7 \mathrm{~m} / \mathrm{s}$ & $67.3 \mathrm{~m} / \mathrm{s}$ \\
\hline$V_{O 2}$ & $35.9 \mathrm{~m} / \mathrm{s}$ & $38.4 \mathrm{~m} / \mathrm{s}$ & $40.5 \mathrm{~m} / \mathrm{s}$ \\
\hline$V_{O 2} / V_{H 2}$ & 0.40 & 0.50 & 0.60 \\
\hline$T_{\text {Inlet }}$ & $294 \mathrm{~K}$ & $294 \mathrm{~K}$ & $294 \mathrm{~K}$ \\
\hline
\end{tabular}

\section{Setup for Visual Flame Length Measurements}

Visual flame images were obtained for a number of 1 atmosphere and 7.5 atmosphere cases. The image acquisition system consisted of a Sony XCD-X700 camera controlled by a Matlab code and triggered by the LabVIEW rocket control program. Images at 1 atmosphere were obtained with an $\mathrm{f} / 1.4,8 \mathrm{~mm}, \varnothing 25.5 \mathrm{~mm}$ lens, a frame rate of 7.5 images per second, and a shutter speed of 2.22ms. For each 1 atmosphere case, 4 runs were made with 30 images taken per run. Images at 7.5 atmospheres were obtained with an $\mathrm{f} / 1.4 \mathrm{D}, 50 \mathrm{~mm}$, Ø52mm lens, a frame rate of 7.5 images per second, and a shutter speed of $2.00 \mathrm{~ms}$. For each 7.5 atmosphere case, 3 runs were made with 25 images taken per run. In addition, single images of the 7.5 atmosphere cases were obtained with a shutter 
speed of $0.10 \mathrm{~ms}$. Note that for pressurized cases, tests were repeated at each window location so the whole flame could be characterized.

Visual flame lengths were obtained by averaging the individual visual flame images for each case. From the average image, the visual flame length was defined as 35 percent of the peak centerline intensity. For the 7.5 atmosphere cases, the images were averaged at each window location and then combined to form a single image of the flame. A typical centerline intensity profile is shown in Fig. 4. The visible light captured in these images is the chemiluminescence associated with the $\mathrm{OH}$ radicals.

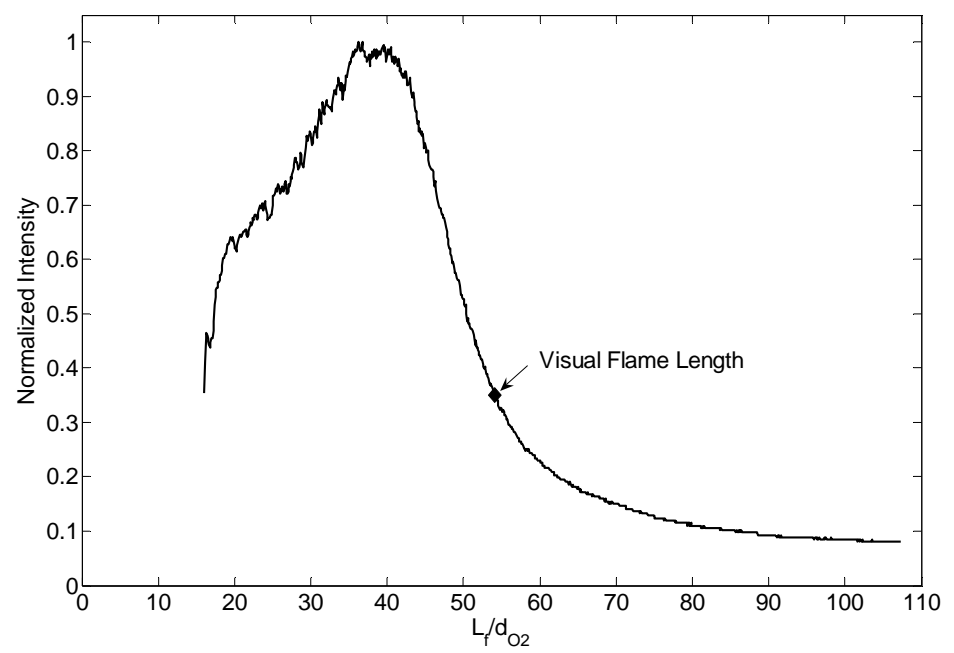

Figure 4. Typical centerline intensity profile. Case 1 from Table 1.

Each test run of the rocket lasted 7.5 seconds with image collection starting 4 seconds into the run. This delay allows start up transients to dissipate and the chamber pressure to approach a constant. Run time is set by the compromise between rocket heating and steady state operation.

\section{Results and Discussion}

Visual flame images of a gaseous hydrogen/oxygen shear coaxial injector in a rocket combustion chamber are presented for chamber pressures of 1 and 7.5 atmospheres. From these images, visual flame lengths are found and plotted. As previously discussed, the experimental apparatus differed for the 1 and 7.5 atmospheres tests. Due to the experimental apparatus, images at 7.5 atmospheres are composite images from multiple window locations.

\section{A. Visual Flame Images at 1 Atmosphere}

Visual flame images were obtained for a number of 1 atmosphere cases. Images from a subset of these cases, listed in Table 1, are presented in Fig. 5. Figures 5a, 5b, and 5c are single images, while Figs. 5d, 5e, and 5f are average images of cases 1,2 , and 3 respectively. Note that the images start $51 \mathrm{~mm}$ above the injector face. Also note that with a shutter time of 2.22ms Figs. 5a, 5b, and 5c can not be considered instantaneous flame images, but still capture part of the turbulent and unsteady nature of the flames. As the images progress from left to right the hydrogen mass flow rate is decreased while the oxygen mass flow rate is held constant. Since the same injector is used in all cases, this means a decreasing hydrogen injection velocity and hence an increasing velocity ratio. All cases are fuel rich, so given an adequate downstream distance, complete oxygen consumption will take place.

The images show that as the hydrogen mass flow rate is deceased, the flame lengths and unsteady nature of the flame increases. While all three flames are turbulent, a shear instability is present in cases 2 and 3 and becomes more pronounced as the hydrogen mass flow rate is decreased. This instability causes the top of the flame to break off and burn downstream. Due to the symmetry seen in the average images, it is clear that the instability has no preferred direction. Shear driven far field mixing is the primary mechanism setting flame length for these flames. With this in mind, a flame with a velocity ratio of 1 should have the longest flame length due to the lack of shear mixing. Case 2, presented in Figs. 5b and 5e, has a velocity ratio of 0.95 while case 3, presented in Figs. 5c and $5 f$ has a velocity ratio of 1.27 . Based on shear layer growth alone one would expect a shorter flame length for case 3 than case 2, however case 3 has the longest flame length. This can be explained by the highly unsteady nature of 
case 3. The instantaneous flame in case 3 is a non-coherent flame with parts breaking off and combusting downstream, which when averaged increases the flame length.

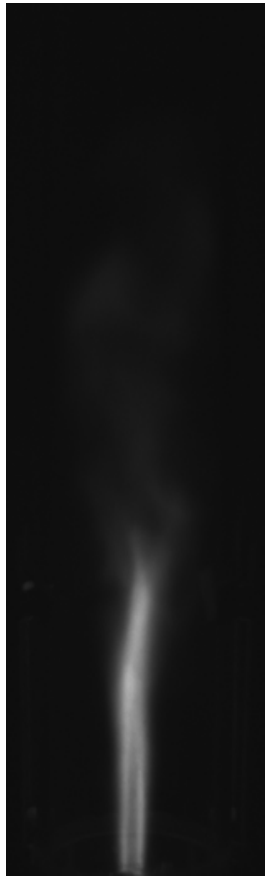

a)

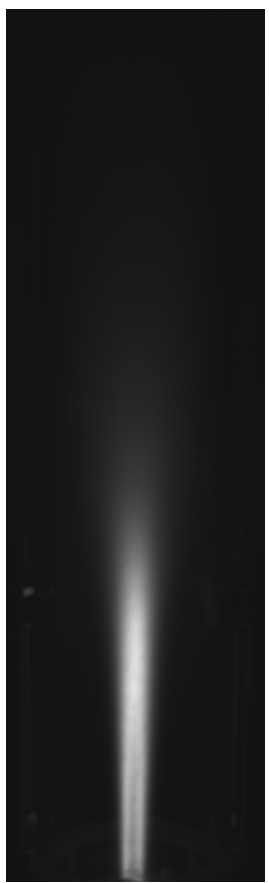

d)

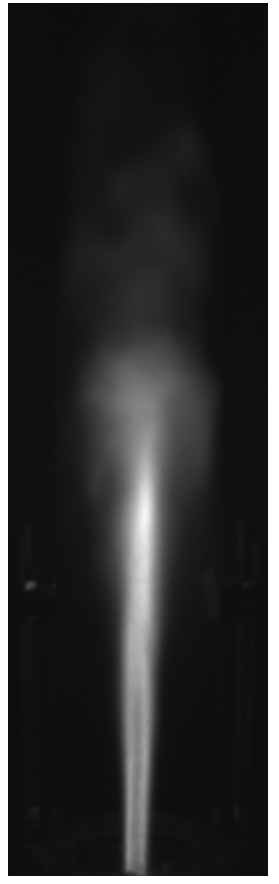

b)

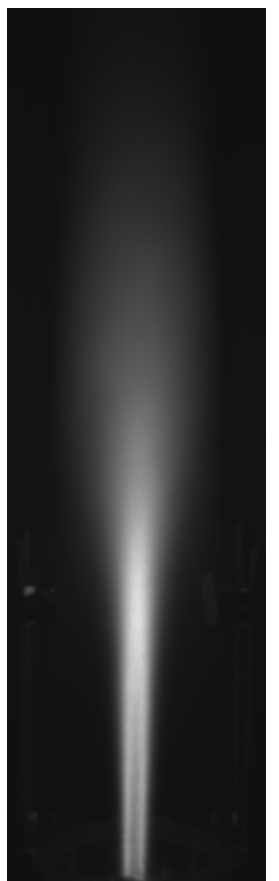

e)

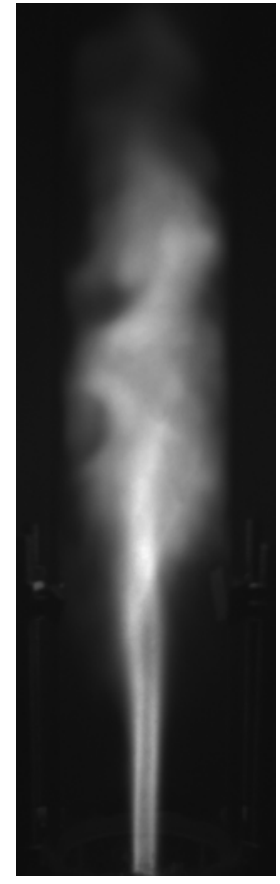

c)

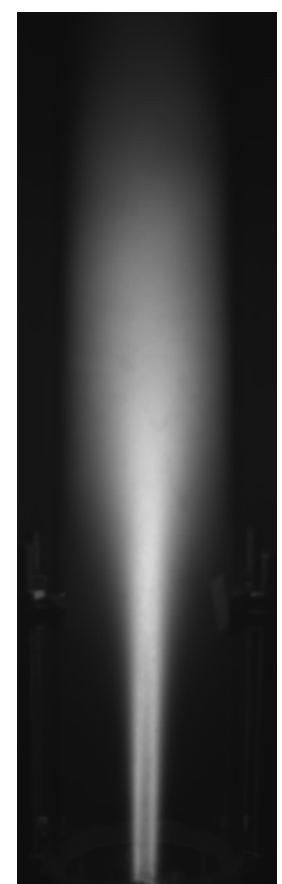

f)

Figure 5. Visual flame images for 1 atmosphere. a) Case 1 single image, b) Case 2 single image, c) Case 3 single image, d) Case 1 avg. image, e) Case 2 avg. image, f) Case 3 avg. image 


\section{B. Visual Flame Images at 7.5 Atmospheres}

Visual flame images were obtained for the three 7.5 atmosphere cases previously defined in Table 2. An instantaneous and a time averaged image of case 6 at the injection face are presented in Fig. 6. A shutter time of $0.10 \mathrm{~ms}$ was utilized for Fig. $6 \mathrm{a}$ and can be considered instantaneous. Time averaged composite images of the three 7.5 atmosphere cases are presented in Fig 7. These images start at a downstream distance of $104.4 \mathrm{~mm}$ from the injector face and continue the length of the combustion chamber. As the images progress from left to right, the velocity ratio is increasing: they are $0.40,0.50$, and 0.60 respectively. This corresponds to a decreasing hydrogen mass flow rate and an increasing oxygen mass flow rate. In addition to the increasing velocity ratio, the velocity difference between the hydrogen and oxygen jets decreases.

Images taken at the injector face, Fig. 6, reveal some important information about these inverse jet flames. First, the flame is attached, which makes the use of shear layer based mixing concepts valid. Second, the instantaneous image shows that flame wrinkling starts occurring before $\mathrm{L} / \mathrm{d}_{\mathrm{O} 2}$ values of 10 . Lastly, the average image shows the linear shear layer growth of the flame front. While the images presented are for case 6 , these results are typical of all cases.

Time averaged images of the three 7.5 atmosphere cases, Fig.7, show the increase in flame length as the velocity ratio increases. As the velocity ratio is increased the velocity difference is decreasing resulting in slower shear layer growth. In addition, the oxygen mass flow rate is increasing so more hydrogen must be mixed in to the center jet to reach the stoichiometric value on the center line. These result in a longer flame length. While the flames for the 7.5 atmosphere cases are highly turbulent, the instabilities that are present in cases 2 and 3 and characterized by the widening of the flame near the tip are not present.

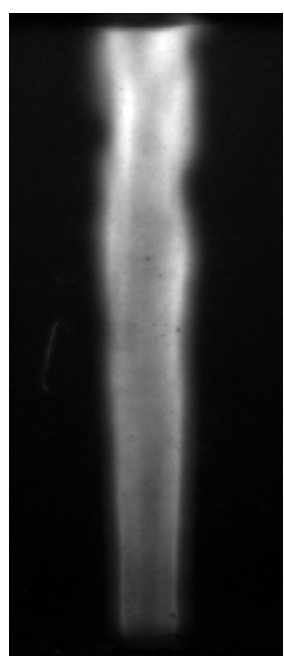

a)

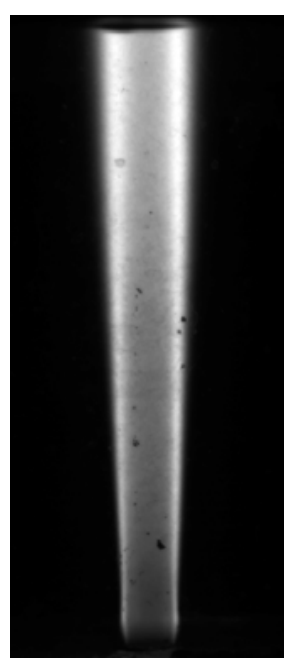

b)

Figure 6. Typical visual flame images at injector face. a) Case 6 instantaneous image, b) Case 6 avg. image

\section{Visual Flame Lengths}

Visual flame lengths were calculated for the 1 and 7.5 atmosphere cases and are presented in Fig. 8. On the horizontal axis is plotted the oxygen mass flow rate divided by the ratio of the density of oxygen at the given chamber pressure to the density of oxygen at 1 atmosphere. Visual flame length is non-dimensionalized by the oxygen tube inner diameter ( $3 \mathrm{~mm})$. For the 1 atmosphere cases, as oxygen mass flow increases, so does the flame length since more hydrogen must be mixed into the oxygen jet to reach stoichiometric conditions on the centerline. For all 1 atmosphere points at a set oxygen flow rate, the flame length increases as the velocity ratio increases. Figure 8 shows that the 7.5 atmosphere flame lengths are similar to those at 1 atmosphere. 


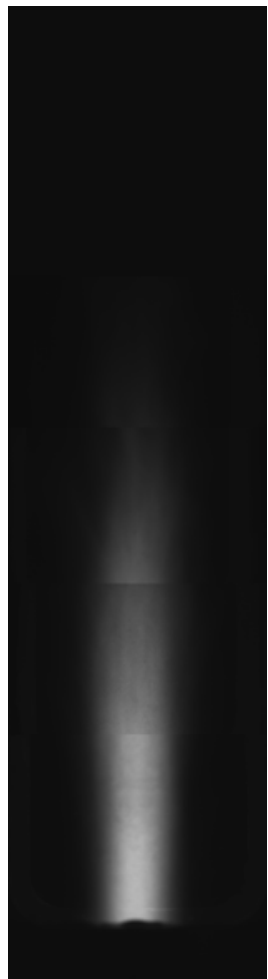

a)

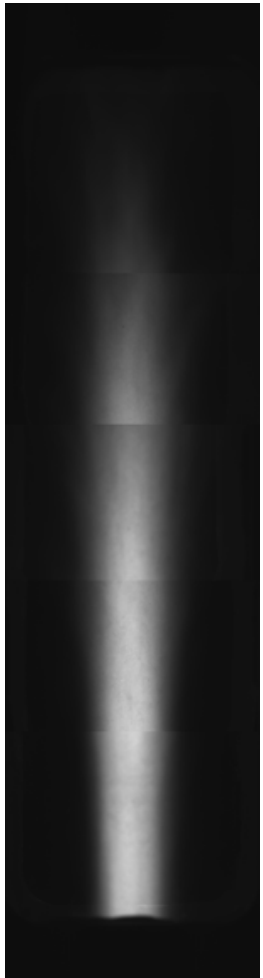

b)

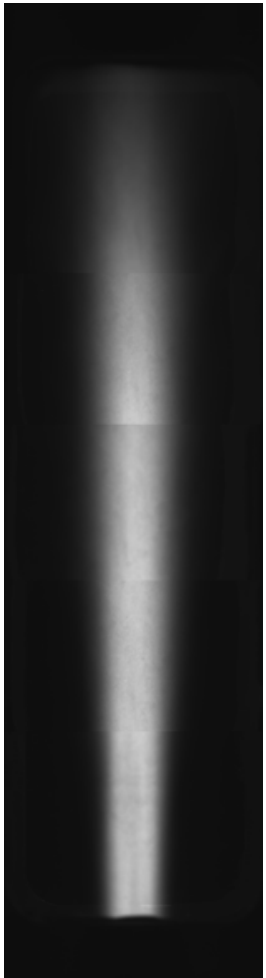

c)

Figure 7. Average visual flame images for 7.5 atmospheres. a) Case 4, b) Case 5, c) Case 6

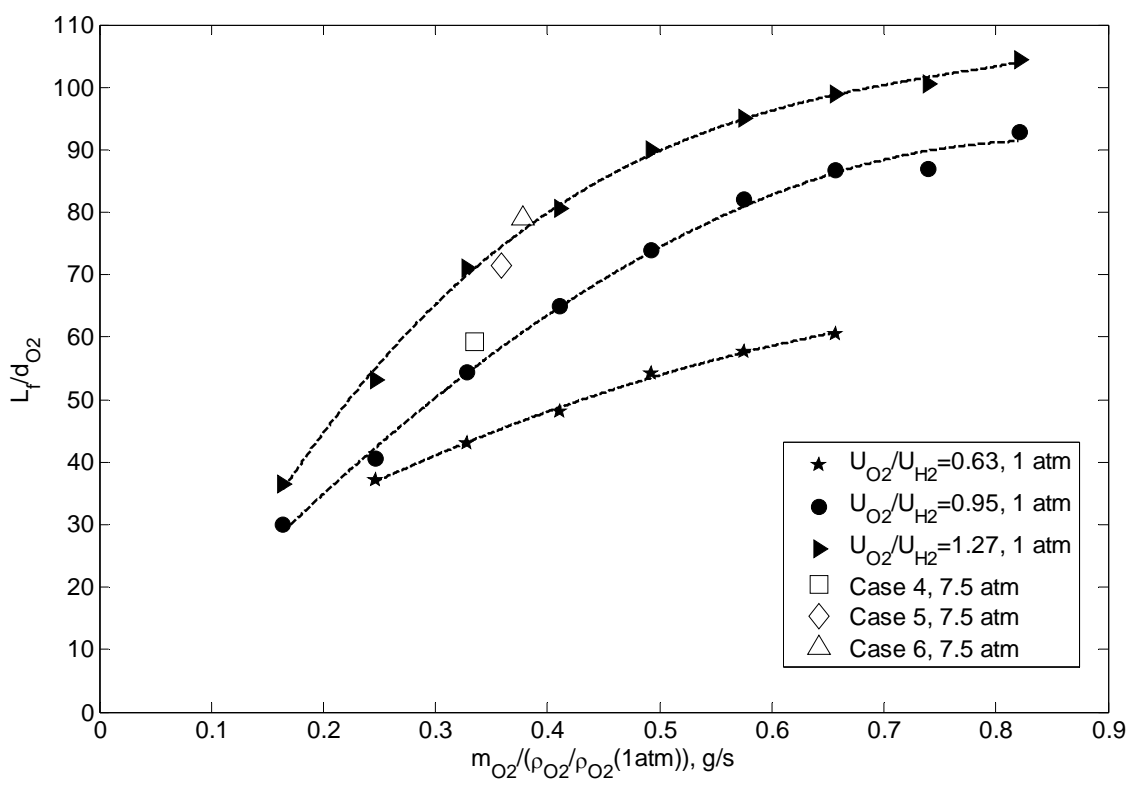

Figure 8. Visual flame lengths for 1 and 7.5 atmosphere cases 


\section{Future Work}

Future work will focus on providing an experimental data base for CFD validation and the derivation of mixing scaling laws for the gaseous shear coaxial rocket injector. To accomplish these goals, the current test matrix will be expanded and the following will be varied: injector diameters, chamber pressures, density ratios, and fuel type. In addition to visual techniques, advanced PLIF techniques will be employed. Acetone PLIF will be utilized to obtain mixture fraction information for non-reacting cases at elevated pressure. OH and NO PLIF will be used; NO will be added as a tracer to obtain mixing parameters and the stoichiometric contour of reacting cases.

\section{Summary}

A new facility has been built at the University of Michigan to study gaseous shear coaxial injectors in a rocket combustion chamber environment. This facility is capable of chamber pressures up to 10 atmospheres, hydrogen mass flow rates up to $2 \mathrm{~g} / \mathrm{s}$ and oxygen flow rates up to $5 \mathrm{~g} / \mathrm{s}$. Visual flame images have been obtained for conditions with chamber pressures of 1 and 7.5 atmospheres. These images show a turbulent, attached, inverse jet flame. From these images, visual flame lengths have been obtained. Expansion of the current test matrix and PLIF techniques are needed to obtain mixing length scaling laws for reacting and non-reacting inverse coaxial jets at elevated pressures.

\section{Acknowledgments}

This work was supported by the Space Vehicle Technology Institute under grant NCC3-989 jointly funded by NASA and DOD within the NASA Constellation University Institutes Project, with Claudia Meyer as the project manager.

\section{References}

${ }^{1}$ Vaidyanathan, R., Tucker, P. K., Papila, N., and Shyy, W., “CFD-Based Design Optimization for a Single Element Rocket Injector,” AIAA 03-0296, AIAA 41 ${ }^{\text {st }}$ Aerospace Sciences Meeting, January 6-9, 2003.

${ }^{2}$ Moser, M. D., Merenich, J. J., Pal, S., and Santoro, R. J., "OH-Radical Imaging and Velocity Field Measurements in a Gaseous Hydrogen/Oxygen Rocket,” AIAA 93-2036, AIAA 29 $9^{\text {th }}$ Joint Propulsion Conference, June 28-30, 1993.

${ }^{3}$ Moser, M. D., Pal, S., and Santoro, R. J., "Laser Light Scattering Measurements in a GO2/GH2 Uni-Element Rocket Chamber," AIAA 95-0137, AIAA 33 ${ }^{\text {rd }}$ Aerospace Sciences Meeting, January 9-12, 1995.

${ }^{4}$ Foust, M. J., Deshpande, M., Pal, S., Ni, T., Merkle, C. L., and Santoro, R. J., "Experimental and Analytical Characterization of a Shear Coaxial Combusting GO2/GH2 Flowfield,” AIAA 96-0646, AIAA 34 ${ }^{\text {th }}$ Aerospace Sciences Meeting, January 15-18, 1996

${ }^{5}$ Foust, M. J., Pal, S., Ni, T., and Santoro, R. J., “Gaseous Propellant Rocket Studies using Raman Spectroscopy,” AIAA 962766, AIAA 32 ${ }^{\text {nd }}$ Joint Propulsion Conference, July 1-3, 1996.

${ }^{6}$ Tucker, P. K., Klem, D. M., Smith, T. D., Farhangi, S., Fisher, S. C., and Santoro, R. J., "Design of Efficient GO2/GH2 Injectors: A NASA, Industry and University Cooperative Effort,” AIAA 97-3350, AIAA $33^{\text {rd }}$ Joint Propulsion Conference, July 6-9, 1997.

${ }^{7}$ Santoro, R. J., "Applications of Laser-Based Diagnostics to High Pressure Rocket and Gas Turbine Combustor Studies," AIAA 98-2698, AIAA $20^{\text {th }}$ Advanced Measurement and Ground Testing Technology Conference, June 15-18, 1998.

${ }^{8}$ Santoro, R. J., Pal, S., and Woodward, R. D., "Rocket Testing at University Facilities," AIAA 01-0748, AIAA 39 ${ }^{\text {th }}$ AIAA Aerospace Sciences Meeting, January 8-11, 2001.

${ }^{9}$ Calhoon, D., Ito, J. and Kors, D., "Investigation of Gaseous Propellant Combustion and Associated Injector-Chamber Design Guidelines,” Aerojet Liquid Rocket Company, NASA CR-121234, Contract NAS3-13379, July 1973.

${ }^{10}$ Soteriou, M. C., and Ghoniem, A. F., "Effects of the Free-Stream Density Ratio on Free and Forced Spatially Developing Shear Layers,” Physics of Fluids, Vol. 7, No. 8, 1995, pp. 2036-2051.

${ }^{11}$ Rehab, H., Villermaux, E., and Hopfinger, E. J., "Flow Regimes of Large-Velocity-Ratio Coaxial Jets,” Journal of Fluid Mechanics, Vol. 345, 1997, pp. 357-381.

${ }^{12}$ Villermaux, E., Rehab, H., “Mixing in Coaxial Jets,” Journal of Fluid Mechanics, Vol. 425, 2000, pp. 161-185.

${ }^{13}$ Murakami, E. and Papamoschou, D., "Mean Flow Development in Dual-Stream Compressible Jets," AIAA Journal, Vol. 40, No. 6, 2002, pp. 1131-1138.

${ }^{14}$ Dimotakis, P. E., “Two-Dimensional Shear-Layer Entrainment,” AIAA Journal, Vol. 24, No. 11, 1986, pp. 1791-1796.

${ }^{15}$ Dahm, W. J. A., and Dibble, R. W., “Coflowing Turbulent Jet Diffusion Flame Blowout,” Twenty-Second Symposium (International) on Combustion, The Combustion Institute, Pittsburgh, PA, 1998, pp. 801-807.

${ }^{16}$ Dahm, W. J. A., and Mayman, A. G., "Blowout Limits of Turbulent Jet Diffusion Flames for Arbitrary Source Conditions," AIAA Journal, Vol. 28, No. 7, 1990, pp. 1157-1162.

${ }^{17}$ Hutt, J. J., and Cramer, J. M., “Advanced Rocket Injector Development at the Marshall Space Flight Center,” AIAA 964266, AIAA Space Programs and Technologies Conference, September 24-26, 1996. 